\title{
Determining damages in ceramic plates by using discrete wavelet packet transform and support vector machine
}

\author{
Mehmet Yumurtaci ${ }^{1}$, Gokhan Gokmen ${ }^{2}$, Tahir Cetin Akinci ${ }^{3}$ \\ ${ }_{1,3}$ Department of Electrical and Electronics Engineering, Afyon Kocatepe University, Turkey \\ ${ }^{2}$ Department of Mechatronics Engineering, Marmara University, Turkey \\ ${ }^{3}$ Department of Electrical Engineering, Istanbul Technical University, Turkey
}

\begin{tabular}{l} 
Article Info \\
\hline Article history: \\
Received Nov 25, 2019 \\
Revised Mar 22, 2020 \\
Accepted Apr 2, 2020 \\
\hline Keywords: \\
Acoustic emission \\
Ceramic material \\
Defect detection \\
Discrete wavelet transform \\
Support vector machine
\end{tabular}

Support vector machine

\begin{abstract}
In this study, an analysis was conducted by using discrete wavelet packet transform (DWPT) and support vector machine (SVM) methods to determine undamaged and cracked plates. The pendulum was used to land equal impacts on plates in this experimental study. Sounds, which emerge from plates as a result of the impacts applied to undamaged and cracked plates, are sound signals used in the analysis and DWPT of these sound signals were obtained with 128 decompositions for feature extraction. The first four components, reflecting the characteristics of undamaged and cracked plates within these 128 components, were selected for enhancing the performance of the classifier and energy values were used as feature vectors. In the study, the SVM model was created by selecting appropriate $\mathrm{C}$ and $\gamma$ parameters for the classifier. Undamaged and cracked plates were seen to be successfully identified by an analysis of the training and testing phases. Undamaged and cracked statuses of the plates that are undamaged and have the analysis had identified different cracks. The biggest advantage of this analysis method used is that it is high-precision, is relatively low in cost regarding experimental equipment and requires hardware.
\end{abstract}

Copyright $@ 2020$ Institute of Advanced Engineering and Science. All rights reserved.

\section{Corresponding Author:}

Tahir Cetin Akinci,

Department of Electrical Engineering,

Electrical and Electronics Faculty,

Istanbul Technical University,

Ayazaga Campus, 34469, Maslak, Istanbul, Turkey.

Email: akincitc@itu.edu.tr

\section{INTRODUCTION}

Methods for determining the deformations in ceramic materials are a very important subject of research. Ceramic materials, especially ceramic plates used in the kitchen, may have visible or micro-level cracks originating from carrying, drying and stacking $[1,2]$. Cracks and deformations, formed in the ceramic plates, can be of different depth and length [2,3]. Their identification can be made in the field of production if cracks are at visible level. On the other hand, if the cracks in the ceramic plates are not visible or at micro-level or if the surface of the ceramic material is coated with glaze, the identification of the cracks can only be determined by using specific methods [1, 4]. Many different methods were used in the literature for determining the deformation in the ceramic materials. Among these methods, the most common methods are radiographic, ultrasound methods, thermal techniques, thermo-mechanical analysis (TMA), dynamic mechanical analysis (DMA), differential scanning calorimetry (DSC), and thermo-gravimetric analysis (TGA). This study can also be seen as an analysis of data obtained by an acoustic emission method (AEM) through data mining method if the study is analysed in the light of a method. AEM has used as a powerful characterization tool for studying the properties of technologically important ceramic and porcelain materials. Acoustic emission test techniques have become a well-known non-destructive method widely used to detect 
and locate faults in ceramic materials. During the production and processing of ceramic materials, various parameters are firmly controlled to impart the desired mechanical and chemical specifications to the end product. The information of thermal stability and reaction kinetics of several phases present in the ceramic materials is of prime importance [5, 6].

One of the most preferred methods for the detection of crack or damage in ceramic materials is computed tomography techniques or XR techniques [7, 8]. This method is used for very special materials or medical materials at the end of production. The method has limitations such as the size of the material and the expensive application technology. Many different studies have been carried out on the tests for the determination of damages in ceramic materials [7, 9-12]. Overall studies are on non-destructive tests. Despite this, the development of signal processing and data analysis methods provided the opportunity to make more detailed analyses. As a result of many Fourier based analyses, low and high frequency components in damaged materials were determined. Infrared thermography is a method used in the characterization and damage determination of ceramic materials. Since composite materials have relatively high emissions depending on the properties and type of material used, they are very suitable for infrared tests with or without surface treatments $[13,14]$. This technique is based on the application of heating a ceramic sample with a short-term energy pulse. The technique is difficult and expensive to apply. In addition, different ultra-sound methods can be performed especially for experimental purposes or for testing sensitive materials $[8,9]$. One of the most widely used methods is the sound emission method. During various deformations occurring in ceramic materials, ultrasonic emission rates and intensity can be associated with the type and spread rates of cracks. Signals from the test sample can be detected using a piezoelectric transducer. In this study, the analysis of the sounds produced by applying a blow on the material was made. The proposed method is more economical and simpler to implement than the mentioned methods. In Table 1 [15], general features about commonly used NDT technical usage are given [8-11]. Here, when the given properties are examined, the method chosen for this study; it will be seen to be economical, easy to use and effective.

Ceramic plates that are undamaged and have different cracks were used in this experimental study. A constant impact was applied to a point specified on the plates and the originated sounds were recorded. While the plate data were analysed by DWPT and the signal energy, the extracted feature vector was applied to SVM method as an input. Therefore, the classification process is carried out. In the analysis, quite successful results were obtained in distinguishing the cracked (damaged) ceramic materials and undamaged ceramic materials.

Table 1. Commonly used NDT technical features [15]

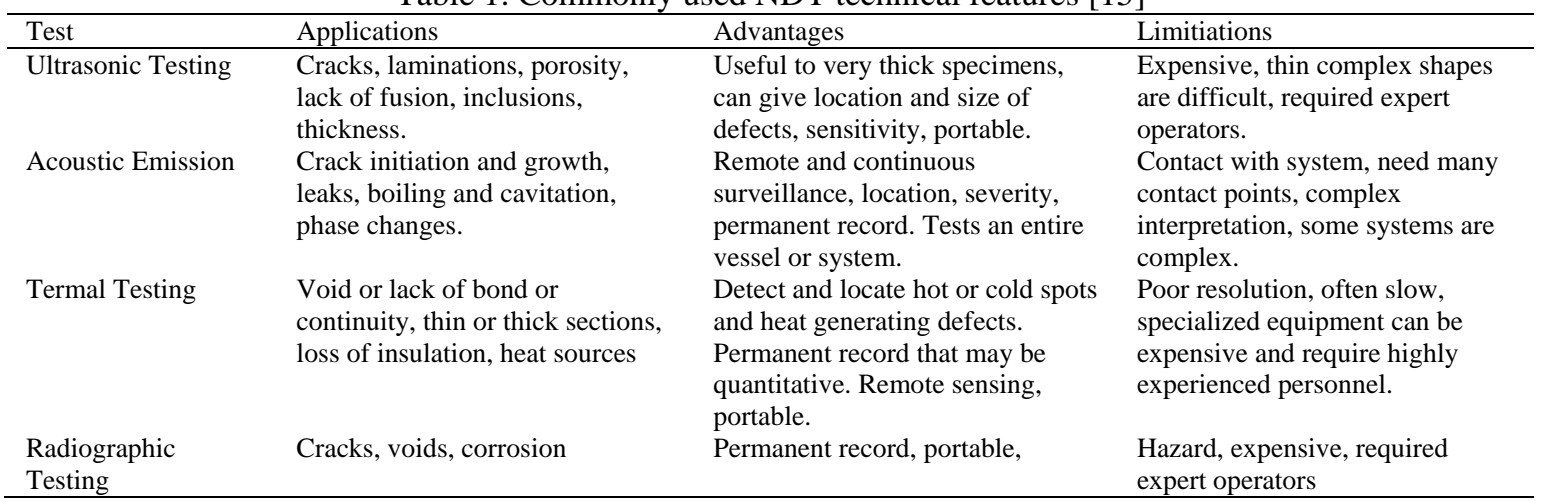

\section{THEORETICAL BACKGROUND AND MATHEMATICAL METHODS}

There are two different approaches of the mathematical methods used in this experimental study. These are DWPT and SVM technique.

\subsection{Discrete wavelet packet transform}

DWPT is a signal analysis method that was developed as an alternative to discrete Fourier transform and is used in many fields of study today [16-18]. DWPT is the separation of the sampled signal into less sampled components like the branches of a tree. This analysis system is carried out with the help of high-pass $(h(n))$ and low-pass filters $(g(n))$ and dawn sampling. The first level analysis is expressed as such for showing $(s(n))$ discrete signal [17-19]. 


$$
\begin{aligned}
& s_{1}^{1}(n)=\sum_{k} s(k) h(2 n-k) \\
& s_{2}^{1}(n)=\sum_{k} s(k) g(2 n-k)
\end{aligned}
$$

Low-pass and high-pass filter responds of $s_{1}^{1}(n)$ and $s_{2}^{1}(n)$ constitutes first level components or decompositions. While the sampling number decreases, the number of components increases [8-10],

$$
\begin{aligned}
& s_{3}^{2}(n)=\sum_{k} s_{1}^{1}(k) h(2 n-k) \\
& s_{4}^{2}(n)=\sum_{k} s_{1}^{1}(k) g(2 n-k) \\
& s_{5}^{2}(n)=\sum_{k} s_{2}^{1}(k) h(2 n-k) \\
& s_{6}^{2}(n)=\sum_{k} s_{2}^{1}(k) g(2 n-k)
\end{aligned}
$$

We can get the second level components $\left(s_{3}^{2}(n), s_{4}^{2}(n), s_{5}^{2}(n), s_{6}^{2}(n)\right)$ when the same approach is applied to the first level components [17-19]:

$$
\begin{aligned}
& s_{7}^{3}(n)=\sum_{k} s_{3}^{2}(k) h(2 n-k) \\
& s_{8}^{3}(n)=\sum_{k} s_{3}^{2}(k) g(2 n-k) \\
& s_{9}^{3}(n)=\sum_{k} s_{4}^{2}(k) h(2 n-k) \\
& s_{10}^{3}(n)=\sum_{k} s_{4}^{2}(k) h(2 n-k) \\
& s_{11}^{3}(n)=\sum_{k} s_{5}^{2}(k) g(2 n-k) \\
& s_{12}^{3}(n)=\sum_{k} s_{5}^{2}(k) h(2 n-k) \\
& s_{13}^{3}(n)=\sum_{k} s_{6}^{2}(k) g(2 n-k) \\
& s_{14}^{3}(n)=\sum_{k} s_{6}^{2}(k) g(2 n-k)
\end{aligned}
$$

When the same procedure is applied to the second level components, the third level components $\left(s_{7}^{3}(n) \ldots . s_{14}^{3}(n)\right)$ are obtained from (4). There are $2^{i}$ amount of component at $i$ level. 128 components $\left(s_{127}^{7}(n) \ldots . s_{254}^{7}(n)\right)$ are obtained with discrete wavelet packet transform from the level 7 [17-19],

$$
\begin{aligned}
& \{s(n)\} \\
& \left\{s_{1}^{1}(n), s_{2}^{1}(n)\right\} \\
& \left\{s_{3}^{2}(n), s_{4}^{2}(n), s_{5}^{2}(n), s_{6}^{2}(n)\right\} \\
& \left\{s_{7}^{3}(n), s_{8}^{3}(n), s_{9}^{3}(n), s_{10}^{3}(n), s_{11}^{3}(n), s_{12}^{3}(n), s_{13}^{3}(n), s_{14}^{3}(n)\right\} \\
& \left\{s_{127}^{7}(n), s_{128}^{7}(n), s_{129}^{7}(n), s_{130}^{7}(n), \ldots \ldots \ldots ., s_{251}^{7}(n), s_{252}^{7}(n), s_{253}^{7}(n), s_{254}^{7}(n)\right\}
\end{aligned}
$$

\subsection{Support vector machine}

SVM, developed by Vapnic and his friends, is a machine learning algorithm widely used in various applications such as pattern recognition, regression and classification since it has the ability of high generalization through structural risk reduction [20]. The purpose of SVM algorithm is to form the most appropriate decision function for reducing classification errors to a minimum as well as to use it in fully estimating the unknown data in the two classes [21]. While $x_{\mathrm{i}}$ is the unknown input data applied to SVM belonging to Class 1 or Class 2 and it is $n$-sized input vector if the output data $\left(y_{\mathrm{i}}\right)$ is 1 then $x_{\mathrm{i}}$ belongs to Class 1 and also $y_{\mathrm{i}}$ is -1 then $x_{\mathrm{i}}$ belongs to Class 2 . If the data are linearly separated, then $f(x)$ expression, provided in separating hyper-plane (6), is determined to be zero [22].

$$
f(x)=w^{T} x+b=\sum_{j=1}^{n} w_{j} x_{j}+b=0
$$


Here, $w$ is an $n$-sized weight vector and $b$ is the scale, they identify the position of separator hyper- plane. If $f\left(x_{i}\right) \geq 1$, then $y_{i}=+1$ and if $f\left(x_{i}\right) \leq 1$, then $y_{i}=-1$ [22]. The case in which SVM and two classes are linearly separated is shown in Figure 1 [23]. In the case of not linear separable two classes, $\xi$ slack variable and $C$ penalty factor are added to $\Phi$ the objective function. In this case, if $\xi_{i} \geq 0$, then unknown data are classified as $w^{T} \cdot x_{i}+b \geq+1-\xi_{i}$ for Class 1 and $w^{T} \cdot x_{i}+b \leq-1+\xi_{i}$ for Class 2 and the objective function is formed like in (7) [24].

$$
\underset{w, b, \xi}{\operatorname{minimise}}\left\{\frac{\|w\|^{2}}{2}+C\left(\sum_{i} \xi_{i}\right)^{k}\right\}
$$

Here, while $C$ is a parameter determined by the user and controls the classification errors of education data, $k$ is a positive integer [15]. Input space that is transferred to high-dimensional space (HDH) with nonlinear $\Phi($.$) transformation called feature space to find the most appropriate separator hyper plane as$ shown in Figure 2. The calculation of the inner product is changed into $K\left(x_{i}, x_{j}\right)=\Phi\left(x_{i}\right) . \Phi\left(x_{j}\right)$ due to this conversion.

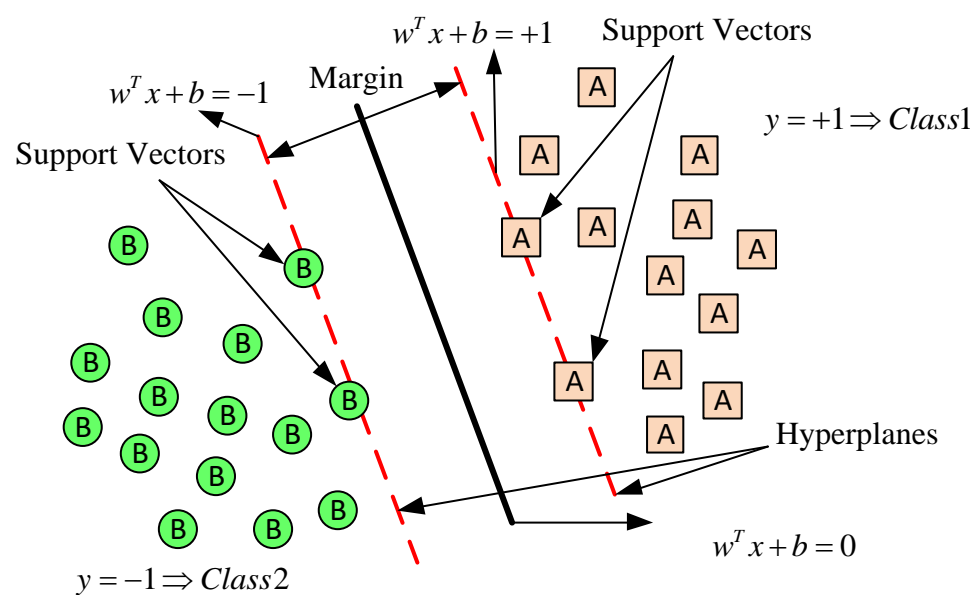

Figure 1. Optimum hyper-plane in the linear separable data set [23]
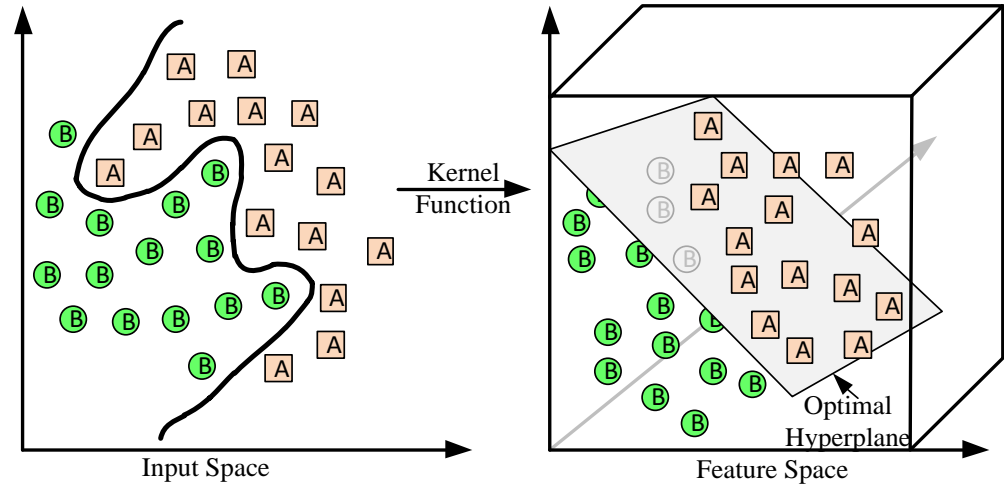

Figure 2. Separation of data that cannot be linearly separated with kernel function in HDH [23]

$K\left(x_{i}, x_{j}\right)$ is the kernel function and represents the inner product in HDH. Radial basis kernel function (RBF) is used to simplify the model in this study, its high computational efficiency and easy implementation advantages [25]. The mathematical expression of RBF is given in (8).

$$
K\left(x_{i}, x_{j}\right)=\exp \left(-\gamma\left\|x_{i}-x_{j}\right\|^{2}\right)
$$


Here, $\gamma$ is the width parameter of RBF kernel. The success of SVM classifier depends on the width of $C$ and $\gamma$ parameters. If the values of $C$ and $\gamma$ parameters are selected larger, the generalization ability of the classifier weakens since there would be extreme learning on the training data and the performance in test data get to be lower while obtaining high success in training data [26]. The values of $C$ and $\gamma$ parameters should be in $10^{-5}, \ldots, 10^{5}$ conversion range for both of them [27]. The final version of the classification function becomes as in (9) [28].

$$
f(x)=\operatorname{sgn}\left(\sum_{i} \alpha_{i} y_{i} K\left(x_{i}, x_{j}\right) \cdot x+b\right)
$$

\section{EXPERIMENTAL STUDY AND MEASUREMENT SYSTEM}

One type of plate was used in experimental studies. Impact pendulum was used to apply constant impacts on the ceramic plates. Impact Pendulum is a pendulum model developed to produce impact at a constant size $[4,29]$. Impacts of equal size were provided by a small hammer attached to impact pendulum in a way to not to inflict damage to ceramic plate and the sound generated from the plate as a result of the impact was transferred to the data collection system and analysed.

POE 2000 type impact pendulum was used in the implementation. The pendulum was made to apply the same impact intensity on ceramic plates from the same point $[2,1,4]$. As a result of the impacts applied to the ceramic material, sounds, generated from the plates with cracks in their structure and undamaged plates, were transmitted to data collection system with a microphone and were then transmitted to the computer for data processing stage from the data collection system. One undamaged and 9 cracked ceramic plates were used in the study. All of the cracks in ceramic plates were different from each other. The output audio data of the amplifier was transmitted to the computer at a sampling frequency of $44.1 \mathrm{kHz}$ via Advantech 1716L multifunction PCI card and data analysis was performed using Matlab $@$, see Figure 3.

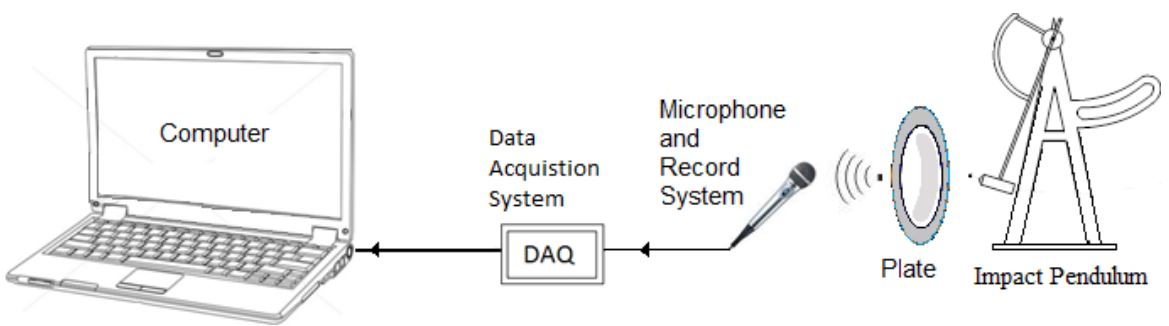

Figure 3. Schematic representation of the data acquisition system

\section{THE PROPOSED CLASSIFICATION METHOD FOR DETERMINING DAMAGE TO THE CERAMIC PLATE}

The first process to be carried out in determining whether the plate is undamaged or cracked (damaged) by using sound frequency recorded from a plate is the inference of feature vector that will be given to the classifier. Wavelet transform, which is widely used in the processing of sound signals in recent years, was made use of. DWPT, which provides a detailed analysis of both high frequency and low-frequency components of the examined signal, was preferred. 128 components of a sound signal with DWPT from $7^{\text {th }}$ level $\left(2^{7}\right)$ in $172,2656 \mathrm{~Hz}$ frequency range was obtained by using db20 wavelet [18].

The number of data in each level decreases in half while conducting decomposition by analysis filters and thus frequency also decreases in half. The frequency range of the components at the seventh level was determined to be between $0 \sim 22050 \mathrm{~Hz}[17,18,30,31]$. While sound signal, obtained from the plate was given in; a) parts of Figures 4-13, DWPT components were given in, b) parts of the related figures.

Each of the 128 components, which we obtained from our main signal and have different frequency range, consists of 565 samples. We need more time and memory for processing. The signal energy, given in (10), was used for reducing the data size without losing the signal's feature.

$$
E=\sum_{n=1}^{N}|v[n]|^{2}
$$

In (10), while $v$ indicates a signal, $N$ indicates data number and $E$ indicates the energy value of $v$ signal [32]. Each component will have a data value using this and the feature vector is reduced to a total of $1 \times 128$ in size at $7^{\text {th }}$ level DWPT. It is necessary to remove features which have little effect or no help within 
the feature vector for performing fast classification process and keeping the generalization ability of the classification [33]. When the feature vector of 1x128 in size was analysed in detail, the impacts of the first 4 components in 10 plates are similar as seen in Figure 14. The components with the frequency ranges of $0-127,2656 \mathrm{~Hz}, 127,2656-344,5312 \mathrm{~Hz}, 344,5312-471,7968 \mathrm{~Hz}, 471,7968-599,0624 \mathrm{~Hz}$ are more effective than other components. The amplitude value of these components is greater than the other components. Therefore, the feature vector of $1 \times 4$ in size, consisting of the energy values of these components, will be applied as an input to the classifier. There are two categories of plates including undamaged and cracked (damaged). While the label of "l" was used for cracked plates, label " 2 " was used for the undamaged plate. Matlab@-based Statistical Pattern Recognition Toolbox (STPRtool) software was used in the implementation of SVM method [34].

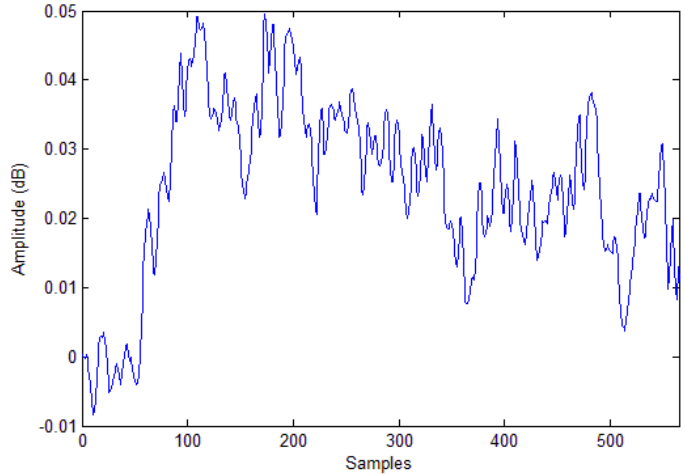

(a)

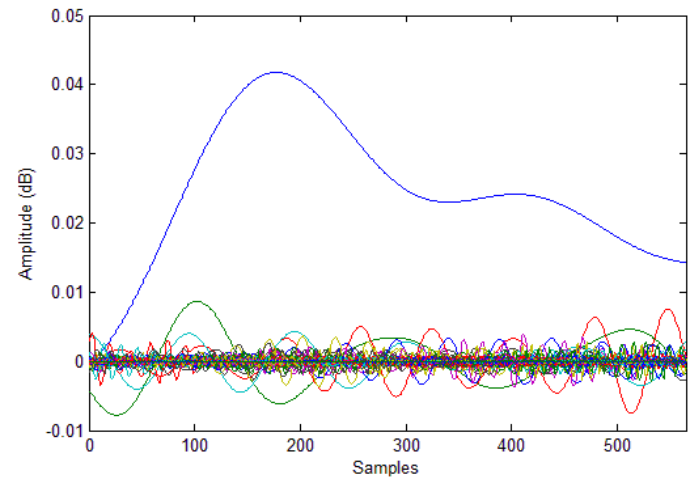

(b)

Figure 4. Undamaged plate: (a) sound signal plot and (b) DWPT decompositions

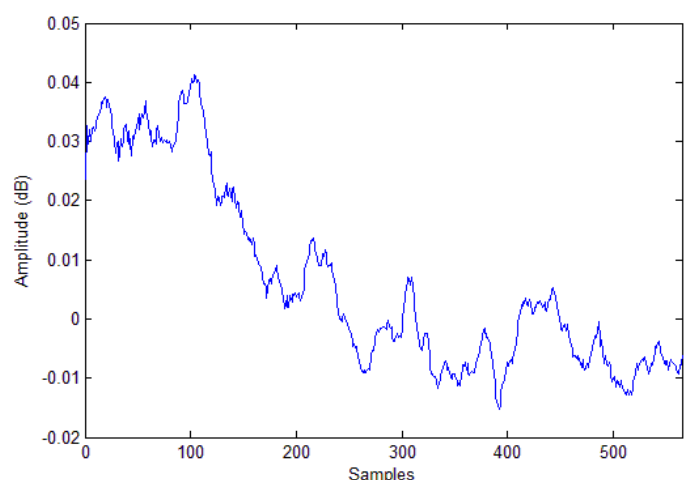

(a)

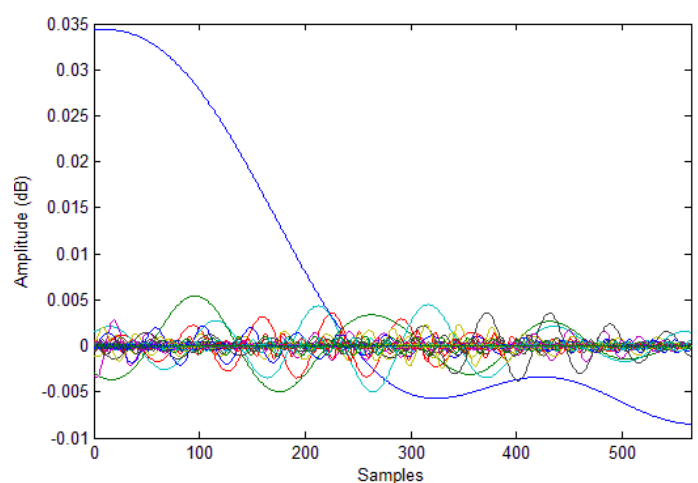

(b)

Figure 5. Cracked plate 1: (a) sound signal plot and (b) DWPT decompositions

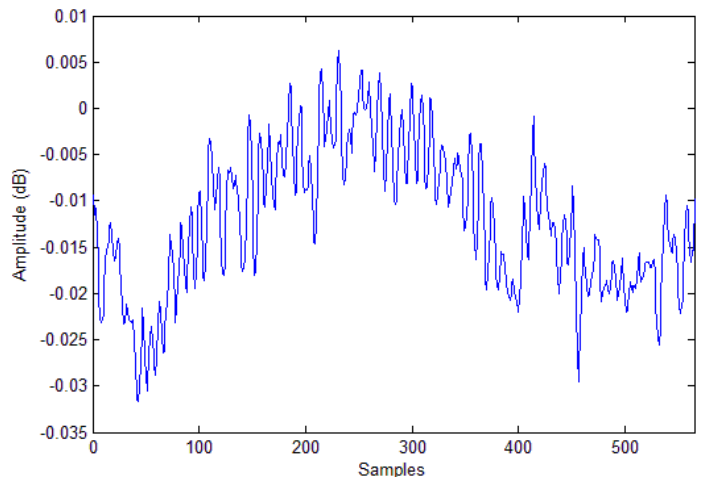

(a)

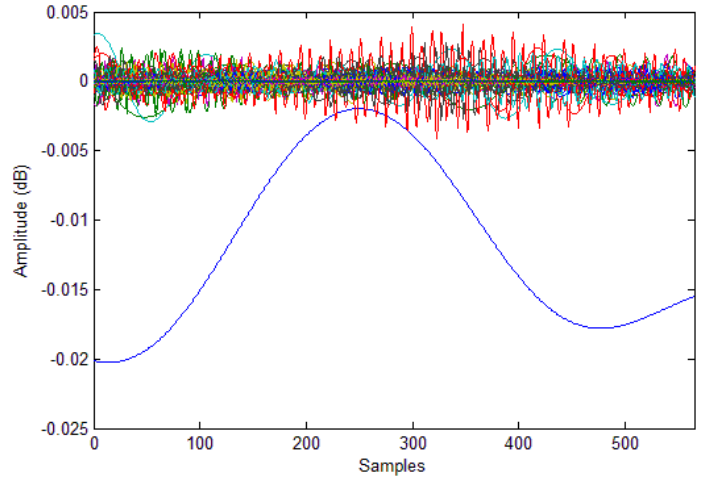

(b)

Figure 6. Cracked plate 2: (a) sound signal plot and (b) DWPT decompositions 
When the graphs between Figures 4-13 are examined, the crack mark of the ceramic plate and its DWPT decompositions are given. Here, ceramic plates with different crack characteristics were chosen especially for analysis. For example, the graphic of Figure 11(a) is very different from other graphics because the crack size of the ceramic plate is deeper. Some deformation (crack) here can be described as micro crack. These micro cracks can only be detected by such tests. In this study, it is aimed to identify cracked plates and robust plates by using DWPT and SWM technique together. Here, the reason for choosing the SWM technique besides the wavelet transformation is due to the fact that the plates are undamaged and the crack probability is limited to two. The feature vectors of undamaged and damaged plates graphic of this selection is given in Figure 14.

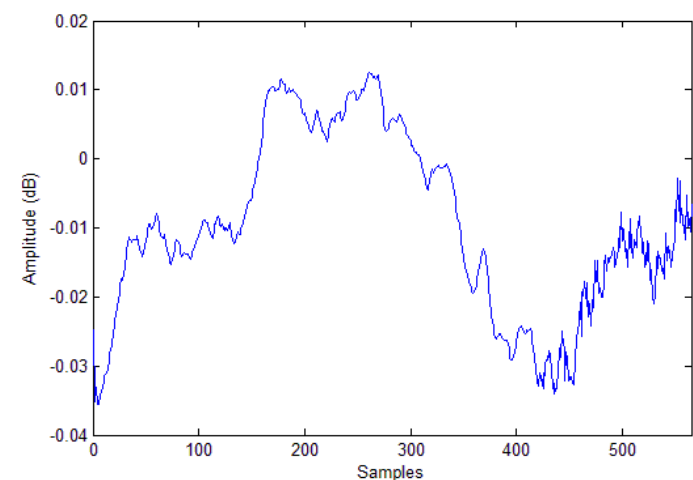

(a)

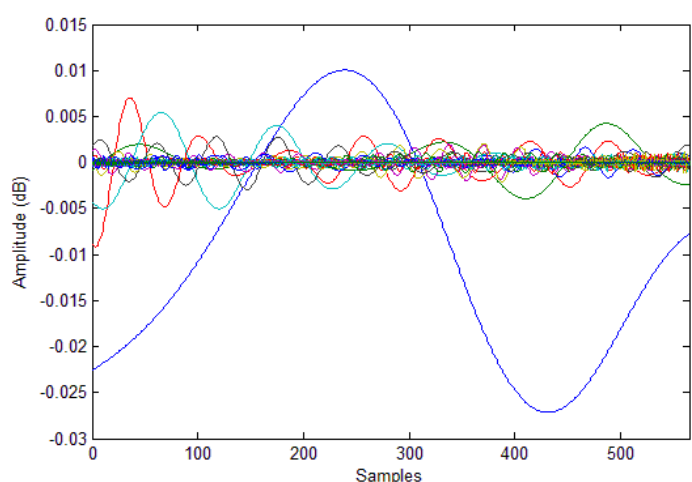

(b)

Figure 7. Cracked plate 3: (a) sound signal plot and (b) DWPT decompositions

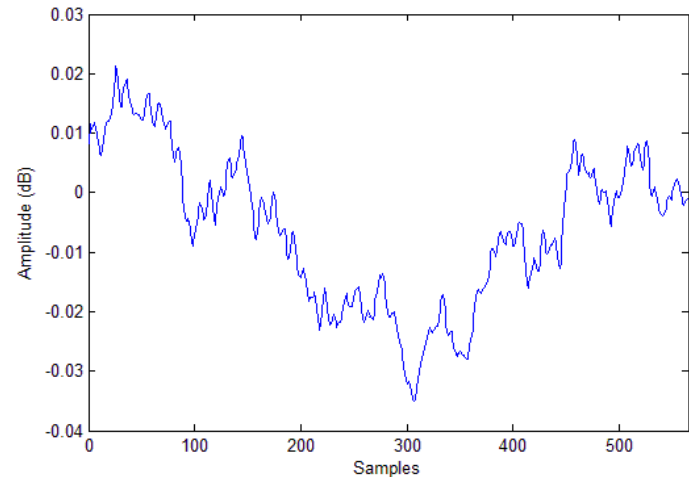

(a)

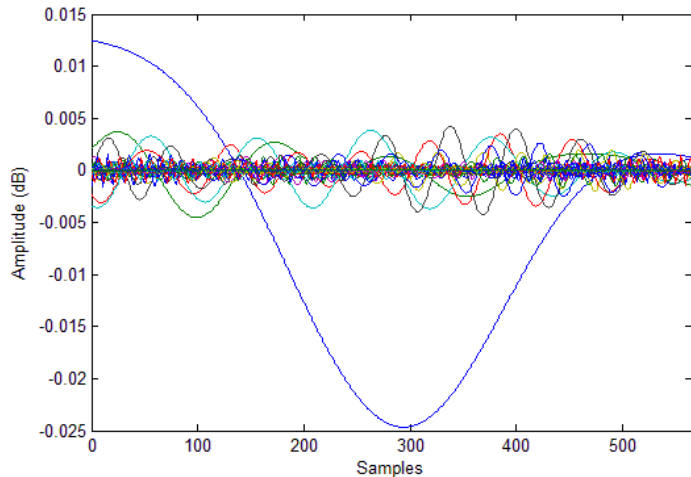

(b)

Figure 8. Cracked plate 4: (a) sound signal plot and (b) DWPT decompositions

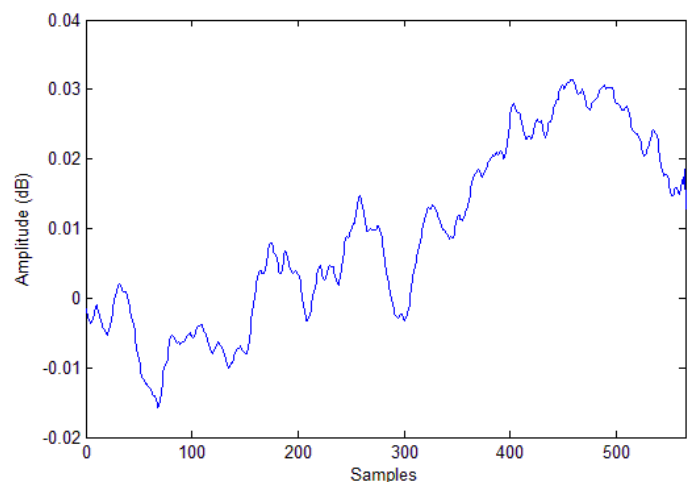

(a)

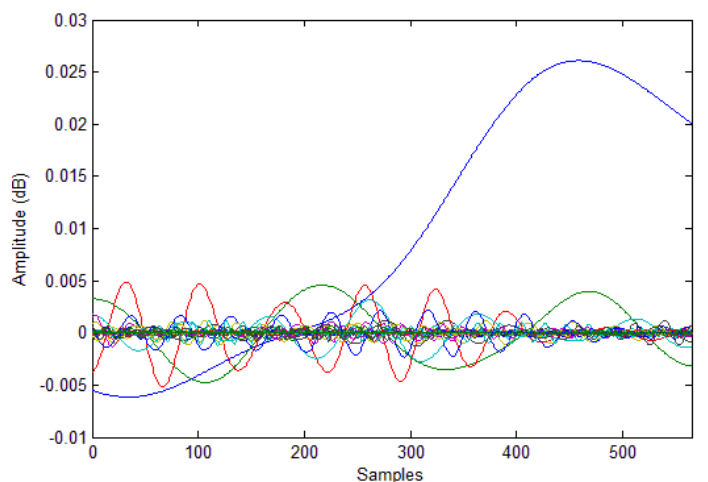

(b)

Figure 9. Cracked plate 5: (a) sound signal plot and (b) DWPT decompositions 
Out of ten plate data, while 1 undamaged and 5 cracked (damaged) plate data were used in the training process of the classifier, the remaining 4 cracked plate data and 1 undamaged plate data were used in the testing process of the classifier. The values of $C$ and $\gamma$ parameters were determined by trial and error method and they are 1000 and 0.01 respectively. As a result of the testing process, 5 plate data were classified and $100 \%$ success was obtained. Block scheme related to the implementation of the suggested method for the identification of damage and durability statuses in plates was given in Figure 15 in details according to the order of process.

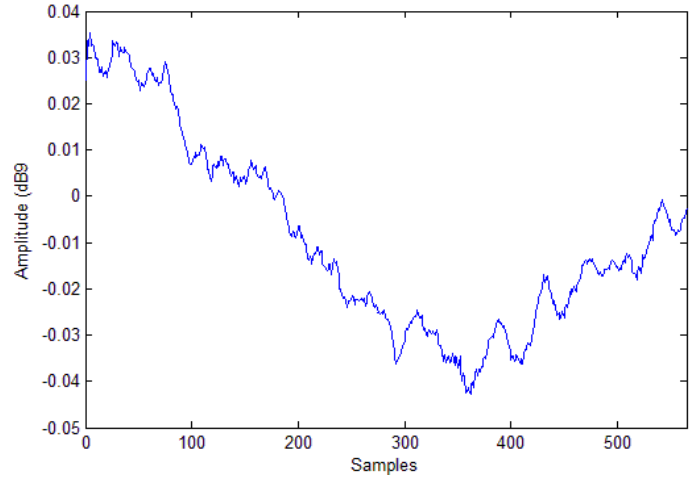

(a)

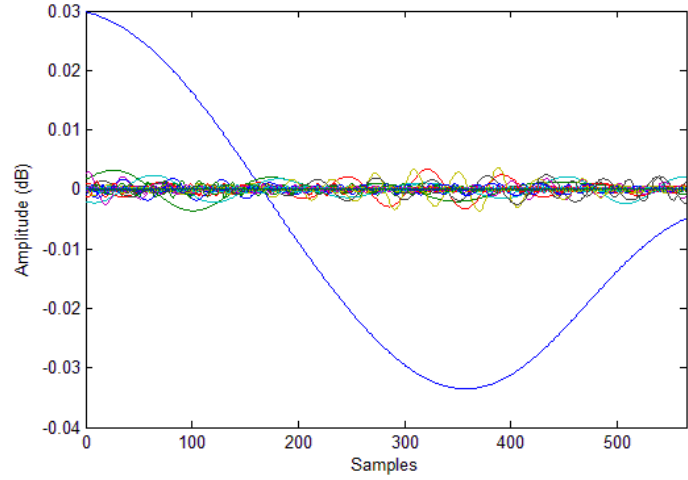

(b)

Figure 10. Cracked plate 6: (a) sound signal plot and (b) DWPT decompositions

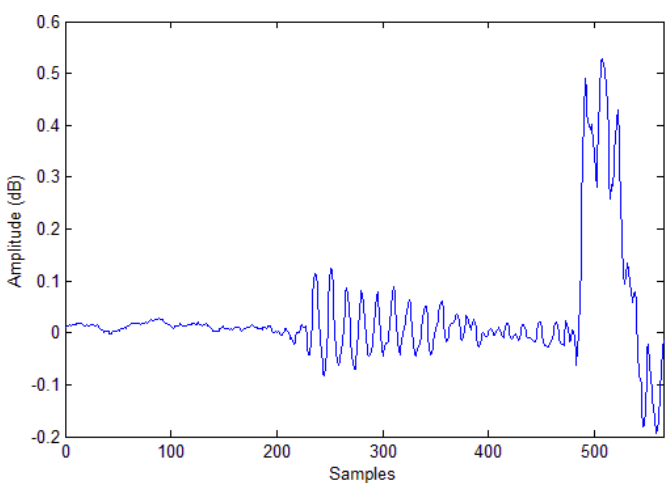

(a)

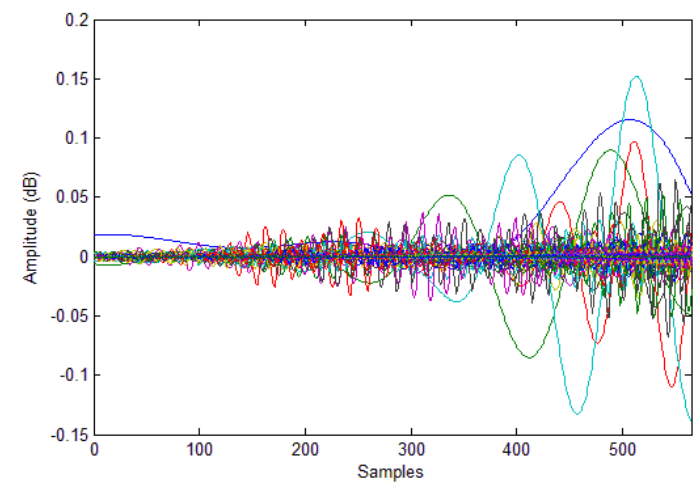

(b)

Figure 11. Cracked plate 7: (a) sound signal plot and (b) DWPT decompositions

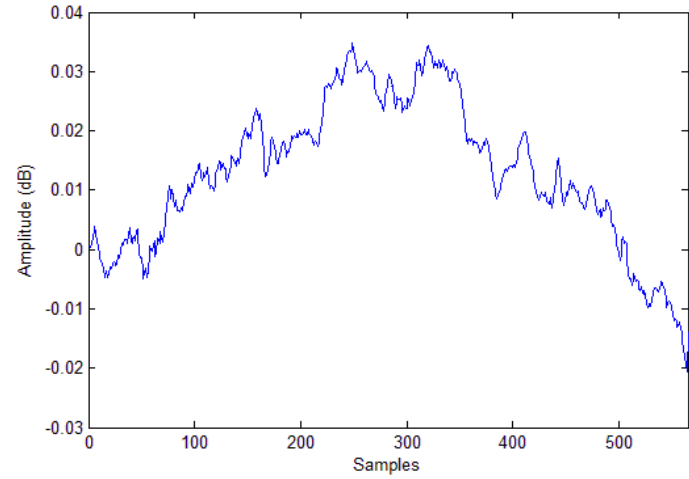

(a)

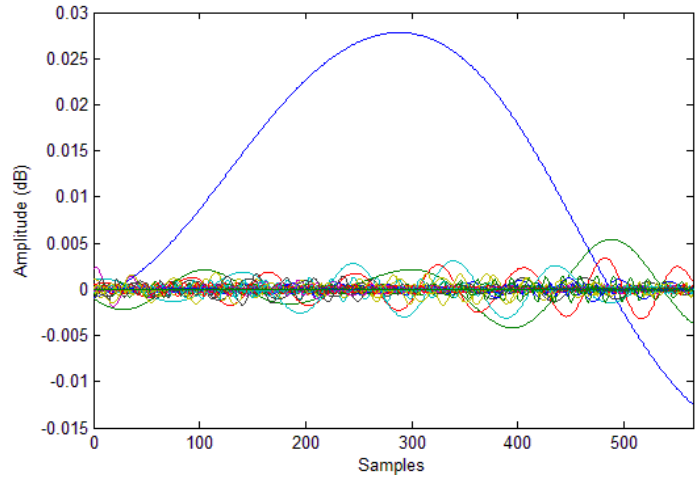

(b)

Figure 12. Cracked plate 8: (a) sound signal plot and (b) DWPT decompositions 


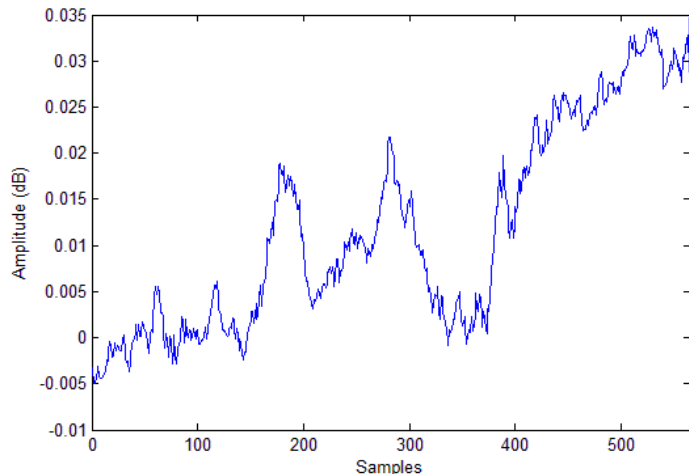

(a)

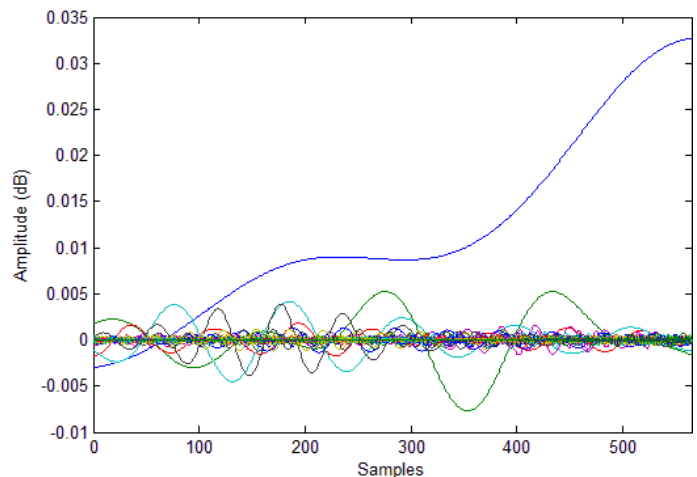

(b)

Figure 13. Cracked plate 9: (a) sound signal plot and (b) DWPT decompositions

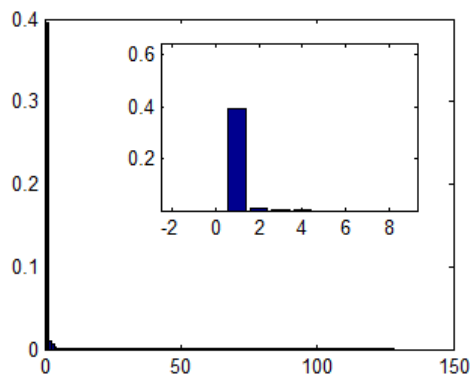

(a)

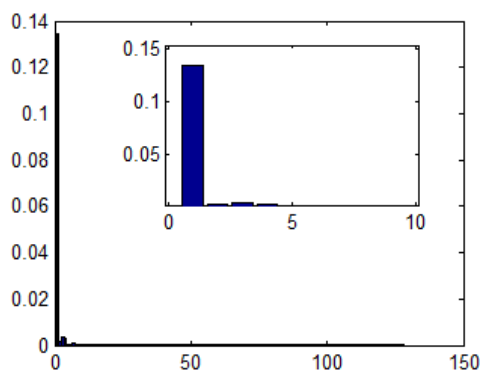

(b)

Figure 14. Feature vectors of undamaged and damaged plates: (a) undamaged plate (b) cracked plate

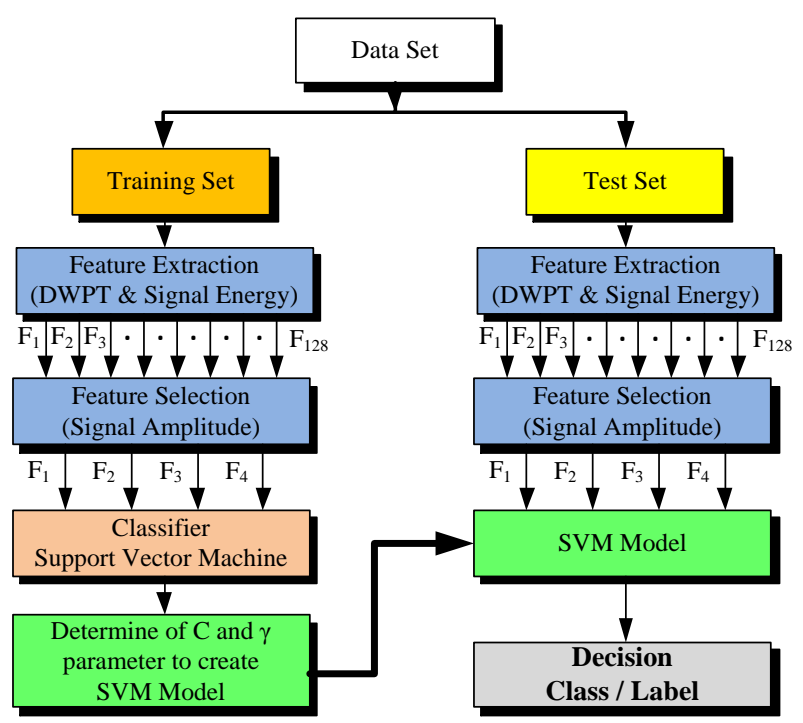

Figure 15. Block schema of the method suggested for plate classification

\section{RESULTS AND DISCUSSIONS}

The technique of analysing the sound coming out of the materials by hitting the ceramic materials gives very successful results in practice [1-4, 35-38]. This technique has been used by scientists for a long time. In this study, DWPT and SVM methods are used together to determine the deformation of the ceramic plates. Short-Time Fourier Transformation (STFT) [4, 35], Continuous Wavelet Transformation (CWT) [1] methods for detecting deformations in ceramic plates have been used in previous studies $[1,3,4]$.

In this study, the signal processing technique and artificial intelligence technique were used together. With this method, more successful results are obtained in terms of comparison and classification. 
Although the ANN method was used for classification in previous studies [18], the SVM technique used in this study is much more successful in the solid-crack detection section. In this context, the method is strong and satisfactory in terms of both analysis and classification.

\section{CONCLUSION}

A DWPT and SVM based analysis method was suggested in this study for determining cracked and undamaged plates. Sounds signals of undamaged and cracked plates were created by an impact pendulum and the 128 decompositions of these sound signals with DWPT was obtained for feature extraction. The first 4 components, which reflect the characteristics of plates among these 128 components, were selected for enhancing the performance of the classifier and energy values were used as feature vectors. SVM model was created by selecting appropriate $\mathrm{C}$ and $\gamma$ parameters for the classifier and undamaged and cracked plates were observed to be identified successfully after training and testing stages.

Only the "undamaged" and "cracked" statuses of the plates were determined in this study. More data on plates are needed for the classification of the damages (cracks) within themselves. It can be possible to determine the damages of the plates by this method after their production stage and before they reach the end-user. The major advantage of this method is its low-cost hardware requirement. Real-time damage assessment can be performed by using an appropriate microphone, impact pendulum and computer.

\section{REFERENCES}

[1] O. Akgun, et al., "The Defect Detection in Ceramic Materials Based on Wavelet Analysis by Using the Method of Impulse Noise," JVE Journal of Vibroengineering, vol. 15, no. 2, pp. 818-825, 2013.

[2] T. C. Akinci, et al., "Application of Artificial Neural Networks for Defect Detection in Ceramic Materials," Archives of Acoustics, vol. 37, no. 3, pp. 279-286, 2012.

[3] T. C. Akinci, et al., "Spectral and Statistical Analysis for Ceramic Plate Specimens Subjected to Impact," Solid State Phenomena, vol. 199, pp. 621-626, 2013.

[4] T. C. Akinci, "The Defect detection in Ceramic Materials Based on Time-Frequency Analysis by Using the Method of Impulse Noise," Archives of Acoustics, vol. 36, no. 1, pp. 1-9, 2011.

[5] A. V. Drosdov, "Investigation on the Microcracking of Ceramic Materials Using the Acoustic Emission Method," Strength of Materials, vol. 46, no. 1, pp. 71-79, 2014.

[6] S. J. Kowalski, and J. Szadzinska, "Non-Stationary Drying of Ceramic-Like Materials Controlled through Acoustic Emission Method," Heat Mass Transfer, vol. 48, no. 12, pp. 2023-2032, 2012.

[7] E. Maire and P. J. Withers, "Quantitative X-ray Tomography," International Materials Reviews, vol. 59, no. 1, pp. 1-43, 2014.

[8] F. Yin, et al., "Methods for Detection of Subsurface Damage: A Review," Chinise Journal of Mechanical Engineering, vol. 31, no. 41, pp. 1-14, 2018.

[9] R. Bohm, et al., "A Quantitative Comparison of the Capabilities of in Situ Computed Tomography and Conventional Computed Tomography for Damage Analysis of Composites," Composites Science and Technology, vol. 110, no. 6, pp. 62-68, 2015.

[10] K. Ehrig, et al., "Comparison of Crack Detection Methods for Analyzing Damage Processes in Concrete with Computed Tomography," International Symposium on Digital Industrial Radiology and Computed Tomography, Berlin, Germany, pp. 1-8, 2011.

[11] A. Mohan and S. Poobal, "Crack Detection Using Image Processing: A Critical Review and Analysis," Alexsandria Engineering Journal, vol. 57, no. 2, pp. 787-798, 2018.

[12] A. Y. Sun and B. F. Ju. "The Acoustic Micro Integrated Detection Technique for Silicon Wafer Processing," Advanced Materials Research, vol. 497, pp. 151-155, 2012.

[13] J. Kim, and P. K. Liaw, "The Nondestructive Evaluation of Advanced Ceramics and Ceramic-matrix Composites," The Member Journal of The Minerals, Metals \& Materials Society (JOM), vol. 50, no. 11, pp. 1-15, 1998.

[14] R. Martin, et al., "Interpreting the Results of Pulsed Thermography Data," Materials Evaluation, vol. 61, pp. 611-616, 2003.

[15] J. Vyas, and R. J. Kazys, "A Review on Nondestructive Techniques and Characteristics of Composite Materials for the Aerospace System," MATEC Web of Conferences, vol. 233, no. 3, pp. 1-8, 2018.

[16] F. Janicek, et al., "A New Protection Relay Based on a Fault Transient Analysis Using Wavelet Transform," Journal of Electrical Engineering, vol. 58, no. 5, pp. 271-278, 2007.

[17] G. Gokmen, "Wavelet Based Reference Current Calculation Method for Active Compensation Systems," Electronics and Electrical Engineering, vol. 108, no. 2, pp. 61-66, 2011.

[18] G. Gokmen, "The Defect Detection in Glass Materials by Using Discrete Wavelet Packet Transform and Artificial Neural Network," JVE Journal of Vibroengineering, vol. 16, no. 3, pp. 1434-1443, 2014.

[19] H. Deng, H. Ling, "Fast solution of Electromagnetic Integral Equations Using Adaptive Wavelet Packet Transform," IEEE Transaction on Antennas and Propagation, vol. 47, no. 4, pp. 674-682, 1999.

[20] Y. Liu, et al., "Fault Diagnosis of Analog Circuit Based on Support Vector Machines," Proceedings of ICCTA, pp. 40-43, 2009.

[21] P G. V. Axelberg, et al., "Support Vector Machine for Classification of Voltage Disturbances," IEEE Transactions on Power Delivery, vol. 22, no. 3, pp. 1297-1303, 2007.

[22] P. K. Dash, et al., "Fault Classification and Selection Identification of an Advanced Series-Compensated Transmission Line Using Support Vector Machine," IEEE Transactions on Power Delivery, vol. 22, no. 1, pp. 67-73, 2007. 
[23] I. Colkesen, and T. Kavzoglu, "Farklı Boyutta Eğitim Örnekleri için destek Vektör Makinelerinin Sınıflandırma Performansının Analizi," III. Uzaktan Algilama ve Coğrafi Bilgi Sistemleri Sempozyumu, Gebze-Kocaeli-Turkey, pp. 161-170, 2010.

[24] J. P. Pedroso, and N. Murata, "Support Vector Machines with Different Norms: Motivation, Formulations and Results," Pattern Recognition Letters, vol. 22, no. 12, pp. 1263-1272, 2001.

[25] X. Wang, et al., "Super-Parameter Selection for Gaussian-Kernel SVM Based on Outlier-Resisting," Measurement, vol. 58, pp. 147-153, 2014.

[26] G. M. Foody, et al., "Classification by Support Vector Machines," IEEE Transactions on Geoscience and Remote Sensing, vol. 42, no. 6, pp. 1335-1343, 2004.

[27] Y. Kumar, et al., "Epileptic Seizure Detection Using DWT Based Fuzzy Approximate Entropy and Support Vector Machine," Neurocomputing, vol. 133, pp. 271-279, 2014.

[28] W. Tong, et al., "Detection and Classification of Power Quality Disturbances Based on Wavelet Packet Decomposition and Support Vector Machines," Signal Processing, 8 $8^{\text {th }}$ International Conference, pp. 16-20, 2006.

[29] J. Bevivino, "The Path from the Simple Pendulum to Chaos," Dynamics at the Horsetooth, vol. 1, no. 1, pp. 24, 2009.

[30] S. A. Saleh, and M. A. Rahman, "New Transient Model for Three-Phase Power Transformers Using a Wavelet Filter Bank," IEEE Transaction on Power Delivery, vol. 20, no. 2, pp. 1409-416, 2005.

[31] C. D. Robertson, et al., "Wavelets and Electromagnetic Power System Transients," IEEE Transaction on Power Delivery, vol. 11, no. 2, pp. 1050-1058, 1996.

[32] M. Yumurtaci, et al., "Classification of Short Circuit Faults in High Voltage Energy Transmission Line Using Energy of Instantaneous Active Power Components Based Common Vector Approach," Turkish Journal of Electrical Engineering \& Computer Sciences, vol. 24 no. 3, pp. 1901-1915, 2016.

[33] D. F. Wang, et al., "Feature Subset Selection for Support Vector Machines Through Sensitivity Analysis," Proceedings of the Third International Conference on Machine Learning and Cybernetics, Shanghai, pp. 4257-4262, 2004.

[34] V. Franc, and V. Hlavac, "Statistical Pattern Recognition Toolbox for MATLAB," User's Guide, Prague, Research Reports of CMP, Czech Technical University, 2010.

[35] P. O. C. Junior, et al., "Feature Extraction Using Frequency Spectrum and Time Domain Analysis of Vibration Signals to Monitoring Advanced Ceramic in Grinding Process," IET Sci. Meas. Technology, vol. 13, pp. 1-8, 2019.

[36] M. A. A. Viera, et al., "A Time-Frequency Acoustic Emission-Based Technique to Assess Workpiece Surface Quality in Ceramic Grinding with PZT Transducer," Sensors, vol. 19, no. 18, pp. 1-19, 2019.

[37] B. Karpuschewski, et al., "Grinding Monitoring System Based on Power and Acoustic Emission Sensors," CIRP Annals-Manufacturing Technology, vol. 49, no. 1, pp. 235-240, 2000.

[38] J. Li, et al., "Modeling of acoustic emission based on the experimental and theoretical methods and its application in face grinding," The International Journal of Advanced Manufacturing Technology, vol. 98, pp. 2335-2346, 2018.

\section{BIOGRAPHIES OF AUTHORS}

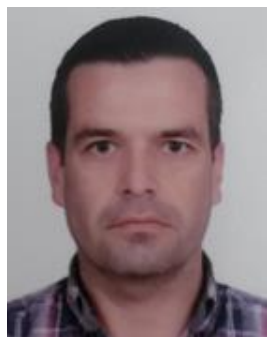

Mehmet Yumurtaci was born in İstanbul, Turkey, in 1980. He received the B.Sc. degree from Marmara University in 2004, the M.Sc. degree from Afyon Kocatepe University in 2007 and the Ph.D. degree from the Marmara University in 2014. His current interests are power systems, transmission line, signal processing, fault classification. He has been working in Afyon Kocatepe University, Technology Faculty, Department of Electrical-Electronics Engineering. E-mail: mehmetyumurtaci@aku.edu.tr

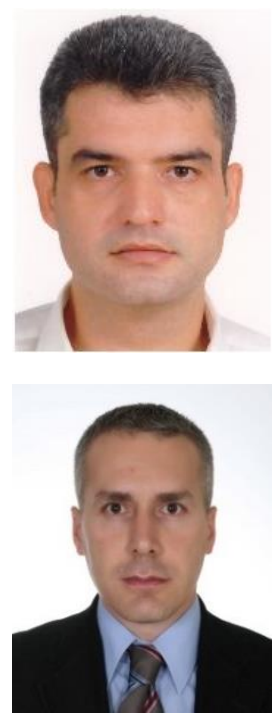

Gokhan Gökmen was born in 1974. He received B.S, M.S and PhD degrees from Marmara University, Istanbul, Turkey. He has been working as a full professor at Marmara University. His current interests are measurement method, signal processing and artificial inteligence techniques. E-mail: gokhang@marmara.edu.tr

T. Cetin Akinci received B.S degrees in Electrical Engineering. M.Sc. and Ph.D. degrees from Marmara University, Istanbul-Turkey. His research interests include artificial neural networks, deep learning, machine learning, image processing, signal processing and, cognitive systems. He has been working as an Associate Professor in Electrical Engineering Department of Istanbul Technical University (ITU) in Istanbul, Turkey. 